\title{
Structural analysis, measurement of a spatial distribution model and classification of the construction of urban areas based on the benefit from urban services: case study - five districts of Zahedan
}

\author{
B. Darvish ${ }^{1}$, R. Sarvar ${ }^{2}$ \& F. Sh. Moghaddam ${ }^{1}$ \\ ${ }^{1}$ Geography and Urban Planning, \\ Faculty of Humanistic and Social Sciences, \\ Science and Research Branch, Islamic Azad University, Iran \\ ${ }^{2}$ Geography Department, Shahr Rey Branch, \\ Islamic Azad University, Iran
}

\begin{abstract}
Heterogeneity of the distribution system of urban services is one of the most important consequences of the rapid growth of urbanization and physical development of cities in the country in the past decades. It has paved the way for social injustice and having urban services land uses in the regions and neighbourhoods of a city. This research has been developed in order to measure the access level of residents in urban areas of Zahedan for required facilities and services. Initially, per capita of status quo of each individual from service uses of a city's status quo was extracted by using data and information of the Zahedan Comprehensive Urban Plan and then the scope and distribution of land uses in five districts of Zahedan were examined by utilizing Williamson and entropy models. Finally, each district was evaluated and ranked in terms of having facilities and services. The results of Williamson and entropy models show unbalanced distribution and lack of services in district 4 due to a large and increasing population. The balanced distribution of services is seen in district 5 and studying the results of having urban services and facilities due to TOPSIS model shows that there is a big difference among urban areas in terms of accessibility and urban services so that the highest amount of TOPSIS for district 5 is 0.894 and the lowest amounts are 0.058 and 0.178 for districts 2 and 4 respectively.
\end{abstract}


Keywords: urban services, spatial distribution, Williamson model, entropy model, TOPSIS technique, Zahedan.

\section{Introduction}

Cities are complex social and physical phenomena that are under pressure of constant development and many qualitative and quantitative changes occur in them (Zavadskas et al. [1]). Since cities are the symbols of human interaction with each other and the environment for the emergence of social man, they should provide a balanced space for growth and the excellence of man and society. Despite injustice in living standards among the residents of a city, there is new phenomenon in none of the cities of the world, but spatial difference of cities has been intensified in less developed countries because of the significant socioeconomic differences and the emergence of below standard settlements. Today, third world countries need planning and identifying facilities and resources in order to strengthen the economic infrastructure and freedom from dependency and the elimination of existing imbalances. Definitely, recognition of the status of the different areas is one of the most important factors to achieve progress in growth and development planning of the country. Spatial, social, cultural and economic differences become evident by classification of areas, therefore, classification requires analysis and studies (Monfarediyan [2]). Today, most people have the common sense that urban areas are undesirable and inappropriate for living and activity since population growth and rapid urbanization in recent decades had adverse effects such as inharmonious spatial distribution of cities, creating neighborhoods on the peripheries, poverty and declining living standards, lack of service centers, and finally inequalities in facilities (Salehi and Reza [3]). Therefore, proportional distribution and balanced sort of urban services include locating these services or uses so that all determined social groups with different spatial features enjoy it as much as possible. The way of distribution urban services can have an influential role in spatial displacement of population and social changes. Since one of the criterions of urban sustainable development and social justice is attention to balanced distribution of services and urban facilities, so distribution of services should be such that social justice be established (Aqababayi [4]). Experimental studies show that imbalance and injustice are characteristics of urbanization of current third world countries. These inequalities are manifested in three levels, namely: Inequalities in livelihood opportunities in rural and urban areas, Inequality from one city to another because of focusing limited resources on capital, economic inequality within the cities among people and a small group of wealthy elite. These imbalances and inequalities may interfere with their performance and national economy expectations in addition to the inherent damage. Unused capacities of more limited areas can be noted as adverse consequences of regional inequality. Also, further use of the power of a region can destroy facilities more quickly. Air and land pollution are the effects of focusing on some areas. Furthermore, abnormal migration from non-prosperous areas to prosperous ones can be regarded as the effects of unbalanced regional growth (Monfarediyan [2]). Local and regional relative capabilities and merits are 
always different due to the influence of different economic, social and environmental factors and this important matter will cause unequal distribution of urban services from an area to another. Therefore, recognition of merits and local and regional capacities are considered as basic principles of development planning and scientific strategies of development become meaningful by explaining status quo. Today, problems caused by poor distribution of urban services such as density, environmental pollution, population displacement and some others have caused the distribution of urban services be one of the most important issues facing most developed and developing countries. Optimal distribution of facilities and services required by citizens at city level should be in a way that all of them have suitable access to them. It will cause save time and cost of citizens because of appropriate provide of citizens' needs and also avoiding their unnecessary displacement. It will provide the necessity of urban sustainability. The process of urban centralization in Iran was started in 1960s after land reform, it was increased with the outbreak of imposed war, and it caused increasing growth of urbanization and double lack of facilities and infrastructure by increasing urban population ad different urban groups proportional with the quality of life have different access to these facilities. Undoubtedly, interruption in service distribution system and its failure is the main effect of the rapid growth of urbanization and uncontrolled growth of urban space that it has appeared without exception in all the major cities in Iran (especially in provincial capitals). Development of service space was not in line with the speedy growth of population and physical development of cities and finally, population growth overtook from levels of service spaces. This leads to failure in spatial and physical structure of most of cities in the world (Salehi and Reza [3]). In Iran like other countries, inadequate distribution of urban services is very disconcerting in different cities and it has changed into a transnational issue.

\section{Theoretical principles}

Disintegration of distribution system is the most important consequences of rapid growth of urbanization and physical development of cities in the country in recent decades. It has paved the way for citizens' social inequality in the enjoyment of these services. Public urban services organize the shape and nature of the physical, social and spatial of city; therefore, injustice in their distribution affects structure, nature of a city, classified segregation of neighborhoods, and in equality in the life quality and urban management faces with serious problems (Kalantari et al. [5]). Focus of service centers on a specific place, not only creates bipolar areas and uptown and downtown, it is followed by an influx of the consumer population to these areas so that it is followed by environmental, traffic, sound and air pollution pressures on the one hand and on the other, intensification of spatial polarization in cities because of absorbing complementary and parallel uses so that cities will face density, undesirable and incompatible with sustainable development environments. One of the main promoting elements of quality of the urban environment is the development of appropriate access indicators considered as one necessary factor for achieving to urban sustainability. 


\subsection{Social justice in a city}

The issue of social justice arises in urban environment in order to access all city dwellers to their needs equally. Inattention to it will have very unpleasant consequences such as: suburbanization and too much density in a region, unilateral development of cities, depopulation of some urban areas, land speculation, and dozens of other difficult issues. Therefore, identifying the effects of social justice issue is considered as one of the fundamental elements of urban studies. A city changes to utopia when social justice covers all necessary aspects. The amount and manner of distribution of municipal services can have an influential role in spatial displacement of population and social changes. In this regard, according to the allocation of resources from urban management and the amount of emphasis on social justice, it will be followed by urban population's satisfaction since the allocation of resources along with social justice help citizens to access to urban services and also increase their efficiency. The appropriate and optimal distribution of social, economic, cultural, and sanitary facilities among areas and regions is one of the most important factors avoiding inequalities and development gap, and appropriate spatial distribution of population in the land. Thus, justice in city should follow proportional and appropriate allocation of services and facilities, using actual and potential capacities in the city, eliminating the gap between rich and poor in the city, and preventing the emergence of slums. As a result, any types of urban planning based on social justice in city should be effective both in distribution of needs, public benefits and entitlements and in their allocation. One of the most factors in urban planning is using spaces and appropriate distribution; in other words, spatial justice. In this regard, uses and urban services are effective and useful factors can also establish dimensions of spatial, social, and economic justice in case of establishing more equitably with addressing population's need, increasing public benefit, and attending to entitlement and individual merits. Therefore, disruption of population balance, which the most important its reasons are immigration inside and outside the city, and too much density of uses in special areas, can change urban spaces into spaces contradictory with justice from economic and social dimensions (Harvey [6]). Generally, it can be said that balanced spatial distribution of urban services is considered as one of the most important signs of social justice in a city.

\section{Research method}

In this research, desired data were collected firstly by library and field studies and then quantitative models such as Williamson coefficient, entropy coefficient, TOPSIS model, Arc GIS and Excel software for diagrams of spatial distribution of urban services in Zahedan were used. Current uses of each urban area were extracted from land use of Zahedan in detailed plan. In order to measure prosperity level of residents in urban areas, the per capita of each use was obtained. Studied uses in this research are explained in table 1 on the basis of available regulations and criteria. 
Table 1: Type of land uses and subgroups based on the regulations of policy management and planning organization (source: Taqvayi and Kiyoumarsi [7]).

\begin{tabular}{|c|c|}
\hline $\begin{array}{c}\text { Type of land use } \\
\text { Business }\end{array}$ & $\begin{array}{c}\text { Sub-groups } \\
\text { Business centers in the city (market, services, Shopping malls, wholesale } \\
\text { shop, private offices, banks, etc.) } \\
\text { Neighborhood commercial (retail, community services), non-permanent } \\
\text { markets (market day per week) }\end{array}$ \\
\hline Training & $\begin{array}{c}\text { Preschool and kindergarten, primary school, middle school, high school, } \\
\text { vocational training centers, technical schools, colleges and post-secondary } \\
\text { educational institution }\end{array}$ \\
\hline Cultural & $\begin{array}{c}\text { Historical and cultural sites (museums, libraries, community halls, cinemas } \\
\text { and theaters) }\end{array}$ \\
\hline Religion & $\begin{array}{c}\text { Mosque, leaning, Shrine centers and religious minorities } \\
\text { Public bathrooms, restrooms, laundry, public toilet }\end{array}$ \\
\hline Sanitary & Hospitals, clinics, health and medical centers \\
\hline Clinical & Stadiums, indoor hall, soccer fields, swimming pools, sports facilities \\
\hline Sport & Parks, recreation areas, public green space, protected green space \\
\hline Green space & \\
\hline
\end{tabular}

\subsection{Research territory}

Zahedan is located in the center of Sistan-Baluchistan province in the east of Iran and near the borders of Afghanistan and Pakistan. Zahedan is located in the area of 8123 hectares and the geographic position at longitude 60 degrees 51 minutes 25 seconds east and latitude 29 degrees 30 minutes 45 seconds north. Zehedan is considered to be one of the prosperous city because of having facilities and amenities. Since this city is located in the border of Afghanistan and Pakistan, cultural commonalities with them, transit line of goods and drugs have caused this city be non-prosperous from effective potentials on urban life quality so that most domestic and non-domestic immigrants have selected outskirts as haven. Most of them are in the north and north-east of the city located in districts 3 and 4 in Zahedan. Therefore, in different areas in Zahedan, imbalance and injustice are obvious in terms of access and enjoyment of the required services, so that distribution of some services in the areas is unfair. Their spatial distribution tends to polarization and concentration in some of these areas (districts 5 and 1).

Table 2: The area and population of Zahedan during 1976-2011 (source: Statistical Center of Iran [8]).

\begin{tabular}{cccccc}
\hline Year & 1976 & 1986 & 1996 & 2006 & 2011 \\
\hline Population & $\mathbf{9 3 7 4 0}$ & $\mathbf{2 8 1 9 2 3}$ & $\mathbf{4 1 9 5 1 8}$ & $\mathbf{5 5 2 7 0 6}$ & $\mathbf{5 7 5 1 1 6}$ \\
Area (hectares) & $\mathbf{1 2 8 5}$ & $\mathbf{3 0 2 2}$ & $\mathbf{4 6 5 0}$ & $\mathbf{4 4 6 8}$ & $\mathbf{8 1 2 3}$ \\
\hline
\end{tabular}

Table 3: The area and population of Zahedan areas (2011) (source: researchers' findings).

\begin{tabular}{cccccc}
\hline Area & 1 & 2 & 3 & 4 & 5 \\
\hline $\begin{array}{c}\text { Population } \\
\text { Area }\end{array}$ & $\mathbf{1 1 2 8 1 6}$ & $\mathbf{1 1 3 9 3 2}$ & $\mathbf{1 2 0 0 1 8}$ & $\mathbf{1 1 4 4 7 5}$ & $\mathbf{1 1 3 8 7 5}$ \\
(hectares) & & 679 & 1545 & 1862 & 2223 \\
\hline
\end{tabular}




\section{Research findings}

Urban services include training, medical, sanitary, cultural, commercial, religious, sport, and facilities and equipment issues. We have studied these services at Zahedan areas' level according to the available statistics and data in this research. Williamson is the first one who generalized the issue of income inequality in the region in the field of regional issues. In this research, rankings of areas have been determined in presenting eight types of urban services on the basis of Williamson indicator formula.

$$
V_{i}=\left(\sqrt{\sum_{i=1}^{n}(x i-x n) \frac{p i}{N}} / x n\right.
$$

In this formula " $n$ " is the number of areas, "xi" the per capita of intended indicator in the area of "i", "xn" the per capita of intended indicator in the whole city, "Pi" the population of area, and " $\mathrm{N}$ " is the total population of city (Hataminejad et al. [9]). It is noteworthy that the obtained number in this indicator is between zero and one. Each obtained number which tends to zero shows the reduction of regional inequalities. Williamson indicator shows the extent and distribution of intended land uses at five areas level of Zahedan. According to the obtained results from this indicator among training, sanitary, medical, religion, sport, and

Table 4: The per capita of urban services in Zahedan areas (source: researchers' findings).

\begin{tabular}{lccccc}
\hline Land use & Area 1 & Area 2 & Area 3 & Area 4 & Area 5 \\
\hline Education & $\mathbf{2 . 6 7}$ & $\mathbf{2 . 4 4}$ & $\mathbf{3 . 5 6}$ & $\mathbf{2 . 2 3}$ & $\mathbf{4 . 6 5}$ \\
Health & $\mathbf{0 . 2 1}$ & $\mathbf{0 . 1 9}$ & $\mathbf{0 . 2 7}$ & $\mathbf{0 . 1 7}$ & $\mathbf{0 . 3 6}$ \\
Medical care & $\mathbf{1 . 5 4}$ & $\mathbf{1 . 4 1}$ & $\mathbf{2 . 0 5}$ & $\mathbf{1 . 2 9}$ & $\mathbf{2 . 6 8}$ \\
Business & $\mathbf{2 . 0 6}$ & $\mathbf{1 . 8 8}$ & $\mathbf{2 . 7 4}$ & $\mathbf{1 . 7 2}$ & $\mathbf{3 . 5 7}$ \\
Green space & $\mathbf{3 . 6 7}$ & $\mathbf{1 . 5}$ & $\mathbf{2}$ & $\mathbf{1 . 0 1}$ & $\mathbf{3 . 3}$ \\
Religion & $\mathbf{0 . 6 2}$ & $\mathbf{0 . 5 6}$ & $\mathbf{0 . 8 2}$ & $\mathbf{0 . 5 1}$ & $\mathbf{1 . 0 7}$ \\
Culture & $\mathbf{2 . 1 7}$ & $\mathbf{1 . 1 5}$ & $\mathbf{3 . 2 1}$ & $\mathbf{2 . 6 3}$ & $\mathbf{4 . 7 2}$ \\
Sport & $\mathbf{2 . 1 6}$ & $\mathbf{1 . 9 7}$ & $\mathbf{2 . 8 7}$ & $\mathbf{1 . 8}$ & $\mathbf{3 . 7 5}$ \\
\hline
\end{tabular}

Table 5: Per capita of urban services in Zahedan areas based on the Williamson model (source: researchers' findings).

\begin{tabular}{lccccccc}
\hline Land use & Area 1 & Area 2 & Area 3 & Area 4 & Area 5 & Total & Rank \\
\hline Education & $\mathbf{0 . 1 0 2}$ & $\mathbf{0 . 1 0 4}$ & $\mathbf{0 . 1 0 2}$ & $\mathbf{0 . 1 0 5}$ & $\mathbf{0 . 0 9 5}$ & $\mathbf{0 . 5 0 8}$ & $\mathbf{2}$ \\
Health & $\mathbf{0 . 3 6 7}$ & $\mathbf{0 . 3 7 3}$ & $\mathbf{0 . 3 6 7}$ & $\mathbf{0 . 7 7 7}$ & $\mathbf{0 . 3 4 0}$ & $\mathbf{1 . 8 2 4}$ & $\mathbf{8}$ \\
Medical care & $\mathbf{0 . 1 3 5}$ & $\mathbf{0 . 1 3 6}$ & $\mathbf{0 . 1 3 4}$ & $\mathbf{0 . 1 3 8}$ & $\mathbf{0 . 1 2 4}$ & $\mathbf{0 . 6 6 7}$ & $\mathbf{6}$ \\
Business & $\mathbf{0 . 1 1 6}$ & $\mathbf{0 . 1 1 8}$ & $\mathbf{0 . 1 1 6}$ & $\mathbf{0 . 1 1 9}$ & $\mathbf{0 . 1 0 8}$ & $\mathbf{0 . 5 7 7}$ & $\mathbf{4}$ \\
Green space & $\mathbf{0 . 1 0 8}$ & $\mathbf{0 . 1 2 2}$ & $\mathbf{0 . 1 2 3}$ & $\mathbf{0 . 1 2 6}$ & $\mathbf{0 . 1 1 1}$ & $\mathbf{0 . 5 9 0}$ & $\mathbf{5}$ \\
Religion & $\mathbf{0 . 2 1 3}$ & $\mathbf{0 . 2 1 6}$ & $\mathbf{0 . 2 1 2}$ & $\mathbf{0 . 2 1 8}$ & $\mathbf{0 . 1 9 7}$ & $\mathbf{1 . 0 5 6}$ & $\mathbf{7}$ \\
Culture & $\mathbf{0 . 0 8 1}$ & $\mathbf{0 . 1 1 1}$ & $\mathbf{0 . 0 6 8}$ & $\mathbf{0 . 0 7 4}$ & $\mathbf{0 . 0 5 5}$ & $\mathbf{0 . 3 8 9}$ & $\mathbf{1}$ \\
Sport & $\mathbf{0 . 1 1 4}$ & $\mathbf{0 . 1 1 5}$ & $\mathbf{0 . 1 1 3}$ & $\mathbf{0 . 1 1 7}$ & $\mathbf{0 . 1 0 5}$ & $\mathbf{0 . 5 6 4}$ & $\mathbf{3}$ \\
Total & $\mathbf{1 . 2 3 6}$ & $\mathbf{1 . 2 9 5}$ & $\mathbf{1 . 2 3 5}$ & $\mathbf{1 . 2 7 4}$ & $\mathbf{1 . 1 3 5}$ & - & - \\
Rank & $\mathbf{3}$ & $\mathbf{5}$ & $\mathbf{2}$ & $\mathbf{4}$ & $\mathbf{1}$ & - & - \\
\hline
\end{tabular}


business services at Zahedan urban areas, the least inequality is in district 5 and the most one is in district 4 . Among green space services, the lowest inequality is in district 1 and the most one is in district 4 . In cultural services, the lowest inequality is in district 5 and the most one is in district 2 . In total, district 5 has the lowest inequality and most balances and district 4 has devoted the most inequality and the lowest balances to itself in urban areas of Zahedan.

\subsection{Entropy coefficient}

To measure uniformly the required variables such as distribution of population in urban areas or general services, entropy model can be used (Hekmatniya and Mousavi [10]). According to the theoretic model, when entropy tends to 1, it shows a sign of spatial balance of a variable and less than that number is on the contrary of this case (Varesi et al. [11]). Initially, the coefficient in Zahedan and then at the level of areas have been calculated in this research. The overall structure of the model is as follows (Sudhira [12]):

$\mathrm{H}$ : the amount of absolute Entropy;

Pi: per capita rate of each land use for total i the total per capita of regions;

$\mathrm{N}$ : total of classes;

$\mathrm{K}$ : number of classes.

$$
\begin{array}{ll}
H=-\sum_{i=1}^{n} P i \times \operatorname{Ln}(P i) & \text { Absolute Entropy } \\
G=\frac{H}{L N K} & \text { Relative Entropy }
\end{array}
$$

Table 6: Calculating entropy coefficient in Zahedan, 2011 (source: researchers' calculations).

\begin{tabular}{|c|c|c|c|c|c|c|c|c|}
\hline $\begin{array}{c}\text { Entropy Coefficient } \\
\text { in Zahedan }\end{array}$ & Education & Health & $\begin{array}{c}\text { Medical } \\
\text { Care }\end{array}$ & Business & $\begin{array}{c}\text { Green } \\
\text { Space }\end{array}$ & Religion & Culture & Sport \\
\hline H & -1.570 & -1.571 & 1.571 & -1.571 & -1.507 & -1.570 & -1.517 & -1.570 \\
\hline LN & 1.61 & 1.61 & 1.61 & 1.61 & 1.61 & 1.61 & 1.61 & 1.61 \\
\hline G & 0.975 & 0.976 & 0.976 & 0.976 & 0.936 & 0.975 & 0.943 & 0.975 \\
\hline
\end{tabular}

According to the obtained results in table 6, sanitary, medical, and commercial services at city level have been distributed more uniformly. Generally, among urban services in Zahedan, the rankings of urban services in the measurement of the distribution from the highest to the lowest balance respectively include sanitary, medical, commercial, cultural, religion, sport and green space.

This model shows distribution of urban services at the level of areas on the basis of services' distribution. As coefficient tends to 1, it shows more balance in services, in urban areas. On the basis of obtained results in table 6, district 5 has the most balance and district 4 has the least one among training services. Similarly, among sanitary, medical, commercial, religion, and sport services district 5 has the most and district 4 the least balance. Among green space services, district 1 has the most and district 4 has the least balance, and finally among cultural services, district 5 has the most and district 2 has the least balance. These results 
have been obtained by the Williamson model. The Williamson coefficient and entropy coefficient of urban services in Zahedan have been compared separately for five districts.

Table 7: Calculating the entropy coefficient in Zahedan (source: researchers' findings).

\begin{tabular}{llllll}
\hline Land use & Area 1 & Area 2 & Area 3 & Area 4 & Area 5 \\
\hline Education & $\mathbf{- 0 . 1 8 8}$ & $\mathbf{- 0 . 1 8 1}$ & $\mathbf{- 0 . 2 1 0}$ & $\mathbf{- 0 . 1 7 3}$ & $\mathbf{- 0 . 2 2 4}$ \\
Health & $\mathbf{- 0 . 1 8 9}$ & $\mathbf{- 0 . 1 8 1}$ & $\mathbf{- 0 . 2 0 8}$ & $\mathbf{- 0 . 1 7 2}$ & $\mathbf{- 0 . 2 2 5}$ \\
Medical care & $\mathbf{- 0 . 1 8 8}$ & $\mathbf{- 0 . 1 8 1}$ & $\mathbf{- 0 . 2 0 9}$ & $\mathbf{- 0 . 1 7 3}$ & $\mathbf{- 0 . 2 2 4}$ \\
Business & $\mathbf{- 0 . 1 8 8}$ & $\mathbf{- 0 . 1 8 0}$ & $\mathbf{- 0 . 2 1 0}$ & $\mathbf{- 0 . 1 7 3}$ & $\mathbf{- 0 . 2 2 4}$ \\
Green space & $\mathbf{- 0 . 2 2 6}$ & $\mathbf{- 0 . 1 6 5}$ & $\mathbf{- 0 . 1 8 9}$ & $\mathbf{- 0 . 1 3 3}$ & $\mathbf{- 0 . 2 2 3}$ \\
Religion & $\mathbf{- 0 . 1 8 9}$ & $\mathbf{- 0 . 1 8 0}$ & $\mathbf{- 0 . 2 1 0}$ & $\mathbf{- 0 . 1 7 2}$ & $\mathbf{- 0 . 2 2 4}$ \\
Culture & $\mathbf{- 0 . 1 8 0}$ & $\mathbf{- 0 . 1 2 8}$ & $\mathbf{- 0 . 2 1 0}$ & $\mathbf{- 0 . 1 9 6}$ & $\mathbf{- 0 . 2 2 8}$ \\
Sport & $\mathbf{- 0 . 1 8 8}$ & $\mathbf{- 0 . 1 8 1}$ & $\mathbf{- 0 . 2 1 0}$ & $\mathbf{- 0 . 1 7 3}$ & $\mathbf{- 0 . 2 2 4}$ \\
\hline
\end{tabular}

\section{TOPSIS technique}

In the following, the manner of assessment process, privatization, and also explanation of model have been addressed. $\mathrm{n} \times \mathrm{m}$ matrix which has $\mathrm{m}$ as option and $\mathrm{n}$ as criterion are evaluated in TOPSIS method. In this algorithm, it is assumed that each indicator and criterion in decision making matrix has a uniform increasing or decreasing desirability. In this model, each selective agent should have the least distance with ideal factor and the furthest distance with negative ideal factor (Benitez et al. [13]). The best option or factor should be the nearest factor to positive ideal and be the furthest factor to the negative ideal (Wang and Elhag [14]). The phases of implementing TOPSIS algorithm: Forming data Matrix on the basis of " $\mathrm{n}$ " as an indicator and "m" as an option, and Standardizing data and forming standard Matrix

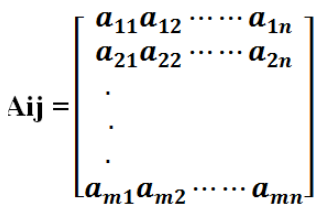$$
\operatorname{Rij}=\left[\begin{array}{l}
r_{11} r_{12} \cdots \cdots r_{1 n} \\
r_{21} r_{22} \cdots \cdots r_{2 n} \\
\cdot \\
\cdot \\
r_{m 1} r_{m 2} \cdots \cdots r_{m n}
\end{array}\right] \quad \begin{gathered}
\mathbf{i j j}=\frac{a i j}{\sqrt{\sum_{k=1}^{m} a_{k j}^{2}}} \\
\sum_{\mathrm{i}=1}^{\mathrm{n}} \mathbf{w i}=\mathbf{1}
\end{gathered}
$$

3. In this phase, the value of each indicator is obtained on the basis of the approaches and expert ideas. In this regard, indicators with more importance have more value. It is noteworthy that total obtained values should be equal for intended indicators of decision maker. In this regard, new Matrix is formed called vij.

$$
\sum_{j=1}^{m} w=1: \text { so that we have }\left[\begin{array}{l}
w r_{11} w r_{12} \cdots \cdots w r_{1 n} \\
w r_{21} w r_{21} \cdots \cdots w r_{2 n} \\
\cdot \\
\cdot \\
\cdot \\
w r_{m 1} w r_{m 2} \cdots \cdots w r_{m n}
\end{array}\right]
$$


4. This phase determines lower ideal alternative: For this purpose, the maximum should be specified in each column in vij Matrix. Accordingly, the number of indicators we will have maximum values.

$$
\boldsymbol{A}^{*}=\left\{\boldsymbol{V}_{1}^{*}, \boldsymbol{V}_{2}^{*}, \ldots \ldots \boldsymbol{V}_{N}^{*}\right\}
$$

5. Determining the alternative of ultimate drop or the reverse of performance limit of each indicator. Here, minimum values or ultimate drop should be identified and shown in vij Matrix.

$$
A^{-}=\left\{V_{1}^{-}, V_{2}^{-}, \ldots \ldots, V_{n}^{-}\right\}
$$

6. Determining a distance criterion for each indicators is obtained by following equation both for ideal alternative and also ultimate drop alternative:

$$
s_{i}^{*}=\sqrt{\sum_{i=1}^{n}\left(v_{i l}-v_{i}^{*}\right)^{2}} \quad s_{i}^{-}=\sqrt{\left.\sum_{i=1}^{n} v_{i l}-v_{i}^{-}\right)^{2}}
$$

7. Forming and determining a coefficient equals ultimate drop alternative divided by their total distance. The mathematical relationship is as follows:

$$
c_{i}^{*}=\frac{s_{i}^{-}}{s_{i}^{-}+s_{i}^{*}} \quad \text { always } \quad 0 \leq c_{i}^{*} \leq 1
$$

The process and ranking technique algorithm based on the similarity to ideal solution are summarized in eight steps as follows:

Step 1: Forming indicator Matrix; $\mathrm{K}$ is alternative and $\mathrm{N}$ is data. According to this research, as table 7 shows, the alternatives consists of five districts in Zahedan and the indicator of available per capita of each urban land uses.

Table 8: Studied alternatives and indexes (source: Central Municipality of Zahedan).

\begin{tabular}{|c|c|c|c|c|c|c|c|c|}
\hline $\begin{array}{c}\text { facilities } \\
\text { Areas }\end{array}$ & Education & Health & $\begin{array}{c}\text { Medical } \\
\text { Care }\end{array}$ & Business & $\begin{array}{c}\text { Green } \\
\text { Space }\end{array}$ & Religion & Culture & Sport \\
\hline 1 & 2.67 & 0.21 & 1.54 & 2.06 & 3.67 & 0.62 & 2.17 & 2.16 \\
\hline 2 & 2.44 & 0.19 & 1.41 & 1.88 & 1.50 & 0.56 & 1.15 & 1.97 \\
\hline 3 & 3.56 & 0.27 & 2.05 & 2.74 & 2.00 & 0.82 & 3.21 & 2.87 \\
\hline 4 & 2.23 & 0.17 & 1.29 & 1.72 & 1.01 & 0.51 & 2.63 & 1.80 \\
\hline 5 & 4.65 & 0.36 & 2.68 & 3.57 & 3.30 & 1.07 & 4.72 & 3.75 \\
\hline
\end{tabular}

Step 2: Normalized matrix is prepared in this step. Since there is a strong possibility that allocated quantitative amounts to the criteria and indicators do not have the same amount, their single dimensions should be eliminated, and then these quantitative amounts change into numbers without dimensions. For this reason, all the allocated amounts to decision making matrices should transform to numbers without dimensions based on the following equation (table 9).

Step 3: After normalizing decision making matrix, criteria weighing occurs. The total weight of the criteria must be equal to 1 and data matrix is specified after multiplying the number of each criterion on the weight of the same criteria. 
Shannon entropy method was used for weighting the criteria in this research (table 10).

Table 9: Matrix of normalized numbers (source: researchers' findings).

\begin{tabular}{|c|c|c|c|c|c|c|c|c|}
\hline Facilities & Education & Health & $\begin{array}{c}\text { Medical } \\
\text { Care }\end{array}$ & Business & $\begin{array}{c}\text { Green } \\
\text { Space }\end{array}$ & Religion & Culture & Sport \\
\hline 1 & 0.98 & 0.08 & 0.57 & 0.76 & 2.39 & 0.23 & 0.70 & 0.80 \\
\hline 2 & 0.82 & 0.06 & 0.48 & 0.63 & 0.40 & 0.19 & 0.20 & 0.66 \\
\hline 3 & 1.75 & 0.13 & 1.01 & 1.35 & 0.71 & 0.40 & 1.53 & 1.41 \\
\hline 4 & 0.69 & 0.05 & 0.40 & 0.53 & 0.18 & 0.16 & 1.03 & 0.55 \\
\hline 5 & 2.99 & 0.23 & 1.72 & 2.29 & 1.94 & 0.69 & 3.30 & 2.41 \\
\hline
\end{tabular}

Table 10: Weighting to indexes using the entropy method (source: researchers' findings).

\begin{tabular}{|ccccccccc}
\hline Index & Education & Health & $\begin{array}{c}\text { Medical } \\
\text { care }\end{array}$ & Business & $\begin{array}{c}\text { Green } \\
\text { space }\end{array}$ & Religion & Culture & Sport \\
\hline weight & $\mathbf{0 . 1 0 2}$ & $\mathbf{0 . 1 0 1}$ & $\mathbf{0 . 1 0 1}$ & $\mathbf{0 . 1 0 0}$ & $\mathbf{0 . 2 0 2}$ & $\mathbf{0 . 1 0 2}$ & $\mathbf{0 . 1 9 0}$ & $\mathbf{0 . 1 0 1}$ \\
\hline
\end{tabular}

Normalized numbers in table 8 are multiplied in the weight of each indicator in table 9 and then standard matrix is created (table 11).

Table 11: Standard matrix of data (source: researchers' findings).

\begin{tabular}{|c|c|c|c|c|c|c|c|c|}
\hline Facilities & Education & Health & $\begin{array}{c}\text { Medical } \\
\text { Care }\end{array}$ & Business & $\begin{array}{c}\text { Green } \\
\text { Space }\end{array}$ & Religion & Culture & Sport \\
\hline 1 & 0.100 & 0.008 & 0.057 & 0.077 & 0.484 & 0.023 & 0.133 & 0.081 \\
\hline 2 & 0.084 & 0.007 & 0.048 & 0.064 & 0.081 & 0.019 & 0.037 & 0.067 \\
\hline 3 & 0.178 & 0.013 & 0.102 & 0.135 & 0.144 & 0.041 & 0.291 & 0.143 \\
\hline 4 & 0.070 & 0.005 & 0.040 & 0.053 & 0.037 & 0.016 & 0.195 & 0.056 \\
\hline 5 & 0.304 & 0.024 & 0.174 & 0.230 & 0.392 & 0.070 & 0.629 & 0.244 \\
\hline
\end{tabular}

Step 4: Determining the alternative distance of "I" from ideal alternative. It means determining the highest performance of each indicator as shown with sign of $A^{*}$ (table 12).

Table 12: Determining the high performance of each index (source: researchers' findings).

\begin{tabular}{ccccccccc}
\hline Index & Education & Health & $\begin{array}{c}\text { Medical } \\
\text { care }\end{array}$ & Business & $\begin{array}{c}\text { Green } \\
\text { space }\end{array}$ & Religion & Culture & Sport \\
\hline A $^{*}$ & $\mathbf{0 . 0 3 0 4}$ & $\mathbf{0 . 0 2 4}$ & $\mathbf{0 . 1 7 4}$ & $\mathbf{0 . 2 3 0}$ & $\mathbf{0 . 4 8 4}$ & $\mathbf{0 . 0 7 0}$ & $\mathbf{0 . 6 2 9}$ & $\mathbf{0 . 2 4 3}$ \\
\hline
\end{tabular}


Step 5: The lowest performance of each indicator is specified by using standard matrix in step 3 (standardized weights matrix) (table 13).

Table 13: Determining the lowest performance of each index (source: researchers' findings).

\begin{tabular}{cccccccccc}
\hline Index & Education & Health & $\begin{array}{c}\text { Medical } \\
\text { care }\end{array}$ & Business & $\begin{array}{c}\text { Green } \\
\text { space }\end{array}$ & Religion & Culture & Sport \\
\hline $\mathrm{A}^{-}$ & $\mathbf{0 . 0 7 0}$ & $\mathbf{0 . 0 0 5}$ & $\mathbf{0 . 0 4 0}$ & $\mathbf{0 . 0 5 3}$ & $\mathbf{0 . 0 3 7}$ & $\mathbf{0 . 0 1 6}$ & $\mathbf{0 . 0 3 7}$ & $\mathbf{0 . 0 5 6}$ \\
\hline
\end{tabular}

Step 6: Determining distance criteria for minimum and maximum alternatives. The results of this step are shown in table 14.

Table 14: Calculating relative distance to the best criteria (source: researchers' findings).

\begin{tabular}{cccccc}
\hline Area & 1 & 2 & 3 & 4 & 5 \\
\hline Si $^{*}$ & $\mathbf{0 . 5 9 4}$ & $\mathbf{0 . 7 9 9}$ & $\mathbf{0 . 5 2 1}$ & $\mathbf{0 . 7 2 8}$ & $\mathbf{0 . 0 9 3}$ \\
$\mathrm{Si}-$ & $\mathbf{0 . 4 6 0}$ & $\mathbf{0 . 0 4 9}$ & $\mathbf{0 . 3 2 6}$ & $\mathbf{0 . 1 5 7}$ & $\mathbf{0 . 7 8 0}$ \\
\hline
\end{tabular}

Step 7: In this step, a coefficient that equals with the division of minimum alternative on (minimum alternative + maximum alternative) is obtained. In other words, relative proximity $(\mathrm{Aj})$ to $\left(\mathrm{A}^{*}\right)$ is calculated by the following equation:

$$
c_{i}^{*}=\frac{s_{i}^{-}}{s_{i}^{-}+s_{i}^{*}} \quad 0 \leq c_{i}^{*} \leq 1
$$

Step 8: Ranking the alternatives fluctuate $\mathrm{Ci}^{*}$ based on descending order of 0 and 1. In this regard, $\mathrm{Ci}^{*}=1$ shows the highest ranking and $\mathrm{Ci}^{*}=0$ shows the lowest one.

Table 15: Ranking options for determining priorities (source: researchers' findings).

\begin{tabular}{cccccc}
\hline Rank & 2 & 5 & 3 & 4 & 1 \\
\hline $\mathrm{Ci}^{*}$ & 0.436 & 0.058 & 0.385 & 0.178 & 0.894 \\
Area & 1 & 2 & 3 & 4 & 5 \\
\hline
\end{tabular}

As indicated in table 15, the used technique has prioritized Zahedan areas based on access to urban facilities and services and presented the points of each neighborhood to score between 0 and 1 . Zero shows the minimum facilities and services and number one shows the maximum access to services. The results of classification of natural separation show that districts 2 and 4 are the most deprived areas with 0.003 and 0.033 respectively. There are a lot of differences with other districts. On the contrary, district 5 is the most prosperous of facilities and services. 


\section{Conclusions and suggestion}

Justice is a concept that has always been a human concern. Considering spatial justice and planning can help to achieve greater civil justice in urban planning. It distributes service concentration in different areas equally. Therefore, the most important criterion for the analysis of spatial justice in the city is the quality of the distribution of public urban services. Justice means proper distribution of services among citizens. Improper distribution causes destroy the justice and increase citizens' dissatisfaction from residence. This research has been done by utilizing Williamson model, entropy coefficient, and TOPSIS technique to determine the rate of prosperity in urban areas. It is one of the methods of determining the distribution of services and facilities in the city and it reveals the inequality in the distribution of municipal services in Zahedan areas. Studies in this city for spatial distribution of urban services represent unequal distribution of facilities and services in the areas. According to the results of the Williamson model, district 4 with 114,475 people has the highest inequality among other districts and district 5 with 113,875 people has the lowest inequality in terms of the distribution of urban services in Zahedan. The results in entropy coefficient for uniform measurement of the intended variables represents a balanced distribution of health, sanitary, and trade facilities with the coefficient of 0.976 and reducing the balance in the distribution of facilities of green space with the coefficient of 0.936 in the city. District 5 has the highest balance in the distribution of urban services and district 4 has the lowest balance in Zahedan. Also, the results of TOPSIS technique show a significant difference in the rate of the most prosperous areas and the most deprived one so that the score of district 5 is 0.894 and it has a great difference with the most deprived areas i.e. 2 and 4 with 0.058 and 0.178 scores respectively. However, the best residential places are located in district 5 and all services benefit from a high per capita while the per capita of district 4 from services is very insignificant and low due to the more marginalized neighborhoods such as Shirabad, Karimabad, Hemmatabad, etc.

\section{References}

[1] Zavadskas, E., Viteikienen, M., \& Saparauskas, j., Sustainable development assessment of cities and their residential districts, Ekologija, vol. 53, pp. 4253, 2007.

[2] Monfarediyan, M., Ranking different urban areas of Shiraz in terms of development, M.A. thesis, Faculty of Administrative Sciences and Economics, Isfahan University, 2007.

[3] Salehi, R., \& Reza, M., Organizing educational spaces (Secondary schools) in Zanjan using GIS, Geographical Researches, issue 52, 2004.

[4] Aqababayi, M., Spatial analysis of fire stations and services in Khomeinishar, M.A. Thesis in Geography and Urban Planning, Faculty of Literature and Humanities, Isfahan university, 2009. 
[5] Kalantari, A., Nasr Esfahani, A., \& Aram, H., The spatial distribution of facilities and services and its adequacy with resident population in Tehran areas, Centre for Studies and Planning in Tehran, 2013.

[6] Harvey, D., Social justice and city, translated by Hessamian, F., Haeri, M. 2nd edition, Tehran: the publication of urban process and planning company, 2000.

[7] Taqvayi, M., \& Kiyoumarsi, H., Ranking areas based on the level of urban facilities and services using TOPSIS model (case study: Abadeh City), the journal of research and urban planning, 2 (5), pp. 23-42, 2011.

[8] Statistical Center of Iran, Population census in Zahedan, 2011.

[9] Hataminejad, H., Vahediyan, B.L., \& Partoun, Z., Measurement of spatial distribution of urban services in Tehran district 5 using Entropy and Williamson model, the Quarterly Journal of Geographical Researches, 29(114), pp. 17-28, 2014.

[10] Hekmatniya, H., \& Mousavi, M.N., The application of model in geography emphasizing on urban and regional planning, Yazd: Elme novin Publication, 2006.

[11] Varesi, H., Rahmati, Q., \& Bastanifar, I., The effects of urban service distribution in spatial imbalance of population (case study: Isfahan urban areas), the Journal of Geography and Development, 2007.

[12] Sudhira, H.S, Urban growth analysis using spatial temporal data, Journal of Society of Remote Sensing vol. 31, 2003.

[13] Benitez, J. M., Martin, J. C., \& Roman, C. Using fuzzy number for measuring quality of service in the hotel industry, Tourism Management, 28(2), pp. 544-555, 2007.

[14] Wang, Y. M., \& Elhag, T.M.S., Fuzzy TOPSIS method based on alpha level sets with an application to bridge risk assessment, Expert Systems with Applications, 31, pp. 309-319, 2007. 